\title{
The Evaluation Method of Gully Village's Ecological Sustainable Development in the Gully Regions of Loess Plateau
}

\author{
Tao Zhang1*, Qinian Hu' ${ }^{1}$, Hiroatsu Fukuda1, Dian Zhou ${ }^{2}$ \\ ${ }^{1}$ Faculty of Environmental Engineering, The University of Kitakyushu, Kitakyushu, Japan \\ ${ }^{2}$ School of Human Settlements and Civil Engineering, Xi'an Jiaotong University, Xi'an, China \\ Email: *zhangtao841120@163.com
}

Received 2 December 2015; accepted 5 March 2016; published 8 March 2016

Copyright (C) 2016 by authors and Scientific Research Publishing Inc.

This work is licensed under the Creative Commons Attribution International License (CC BY).

http://creativecommons.org/licenses/by/4.0/

(c) (i) Open Access

\begin{abstract}
The gully region of Loess Plateau is one of the earliest human settlement areas and the most ecologically sensitive areas in China. It has been facing challenges for future development. Gully village is the smallest social units on Loess Plateau that owns large amount of agricultural population. However, due to inappropriate development planning and lack of developing directions, they are gradually disappearing. Based on the practical investigations of the Gully Regions of Loess Plateau, this paper aims to explore a new way for the future development of gully villages. Firstly, it classifies the gully villages by the distribution of location. Secondly, selecting ecological construction evaluation factors of gully village and completing the quantitative evaluation are applied on the suitability and sensitivity of ecological sustainable development classification. Thirdly, according to the comprehensive evaluation, the developing condition of each gully village is divided into "Good", "General" and "Poor". Finally, this paper figures out the future developing direction for gully villages in different developing conditions.
\end{abstract}

\section{Keywords}

Loess Plateau, Gully Village, Comprehensive Evaluation, Suitability, Sensitivity

\section{Introduction}

\subsection{Background}

The Loess Plateau is located in the west of China, which is covered with $30 \mathrm{~m}$ - $300 \mathrm{~m}$ calcareous yellow soil,

${ }^{*}$ Corresponding author.

How to cite this paper: Zhang, T., Hu, Q.N., Fukuda, H. and Zhou, D. (2016) The Evaluation Method of Gully Village's Ecological Sustainable Development in the Gully Regions of Loess Plateau. Journal of Building Construction and Planning Research, 4, 1-12. http://dx.doi.org/10.4236/jbcpr.2016.41001 
about 530 thousand square kilometers, accounting for 1/18 of total Chinese territory [1]. Gully regions of Loess Plateau is also one of the earliest human settlement areas and one of the most fragile ecological areas in China [2]. The administrative areas of it totally include 6 cities, 18 counties, a population of about 4.3 million, a total area of about 14.8 thousand square kilometers (Figure 1).

Within the area, landscape can be divided into tableland, slope, and gully. Villages' distribution in this region is dispersed and owns obvious local characteristics, mainly distributed in tableland, ditch, slope and gully [3]. Figure 2 shows the mainly village types, including tableland village, slope village and gully village. As the smallest social units, gully villages usually located at the bottom of gully regions and have a large number of agricultural populations. The necessary condition for this distribution is sufficient gap width, so as to ensure the development of villages. These villages are often located at the bottom of gullies that are in the shape of " $U$ ", and often near perennial gully-typed rivers. Such kinds of villages are widely distributed in the Loess Plateau, accounted for $30 \%$ to $40 \%$ of all villages.

Since the 21st century, with the progress of "population transfer to tableland", large number of population who used to live in slope villages and gully villages gradually moved to the tableland. On the one hand, it caused the disappearance of the slope village and gully village. On the other hand, it increased ecological pressure of tableland where was densely populated originally. Therefore, for the ecological and sustainable development of gully villages and even the whole loess plateau, it is very important to explore a scientific way to save resources and use energy effectively, protect ecological environment, improve living environment of local people, and guide the construction of gully villages.

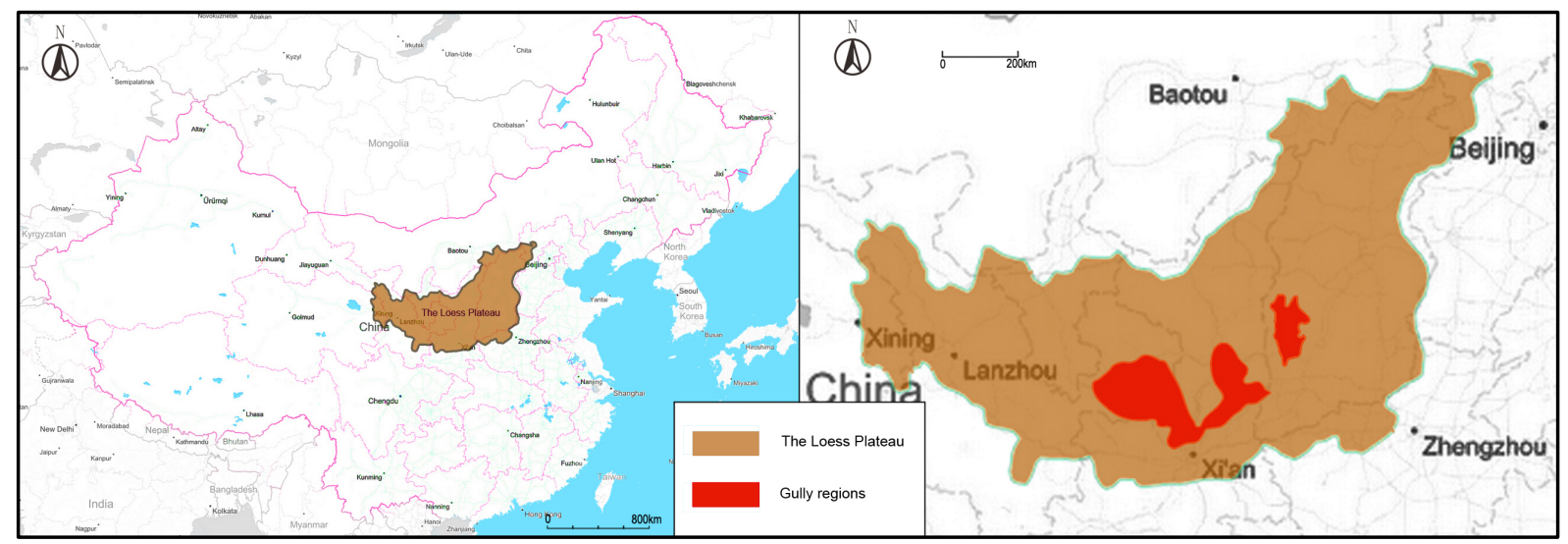

Figure 1. Scale of the loess plateau and gully regions.
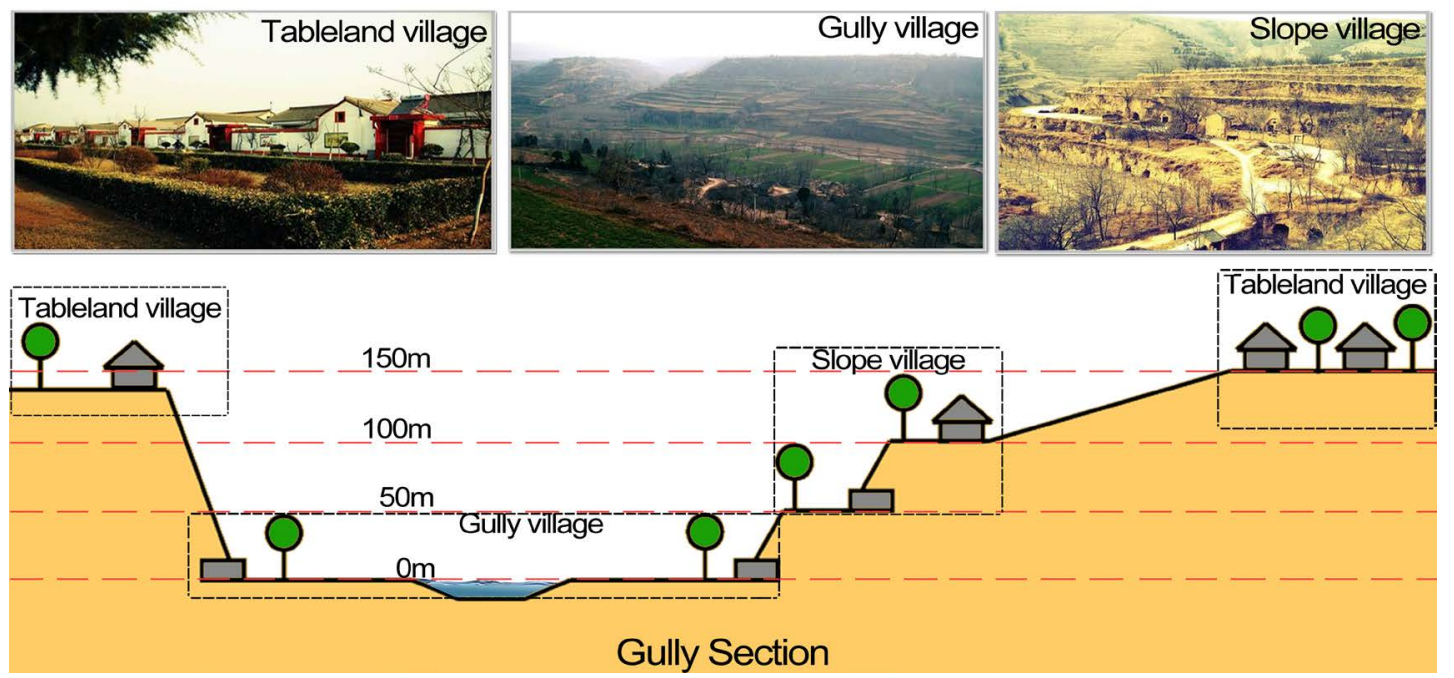

Figure 2. Cross section to show villages' types in gully regions. 


\subsection{Classification of Gully Villages}

Gully villages are located in the gully region of third level tributary. The third level tributary can be identified by length that is about $50 \mathrm{~km}$, and there are $5 \mathrm{~km}$ small scale rivers. The conception here is in compliance with what used in the protection and conservation of soil and water [4]. It is made up by main gullies with rivers and branch gullies without rivers, which are also the smallest settlement typologies in the Loess Plateau [5]. According to the different locations of these gully villages, there are two physical features: villages located in the main gullies and villages in the branch gullies (Figure 3).

1) Villages located in main gullies

This type of villages located in the main gullies of the third level tributary. Gully villages own broad land that is near water sources and main roads. Thus, the village size is larger than those located in gully branches, and high population density area. The following figures show a typical main gully village, the name of that is Zhang Jia He village. There are 135 families, 516 people, 102.33 hectares of cultivated land, and the annual per-capita income is approximately 5000 RMB (816 USD) (Figure 4).

In addition, even in the same third level tributary gully, the distributions of gully villages has different forms. If the villages in the main gullies are close to the gullies junction or plateau surface, the developing conditions of these villages are quite better than other villages [6].

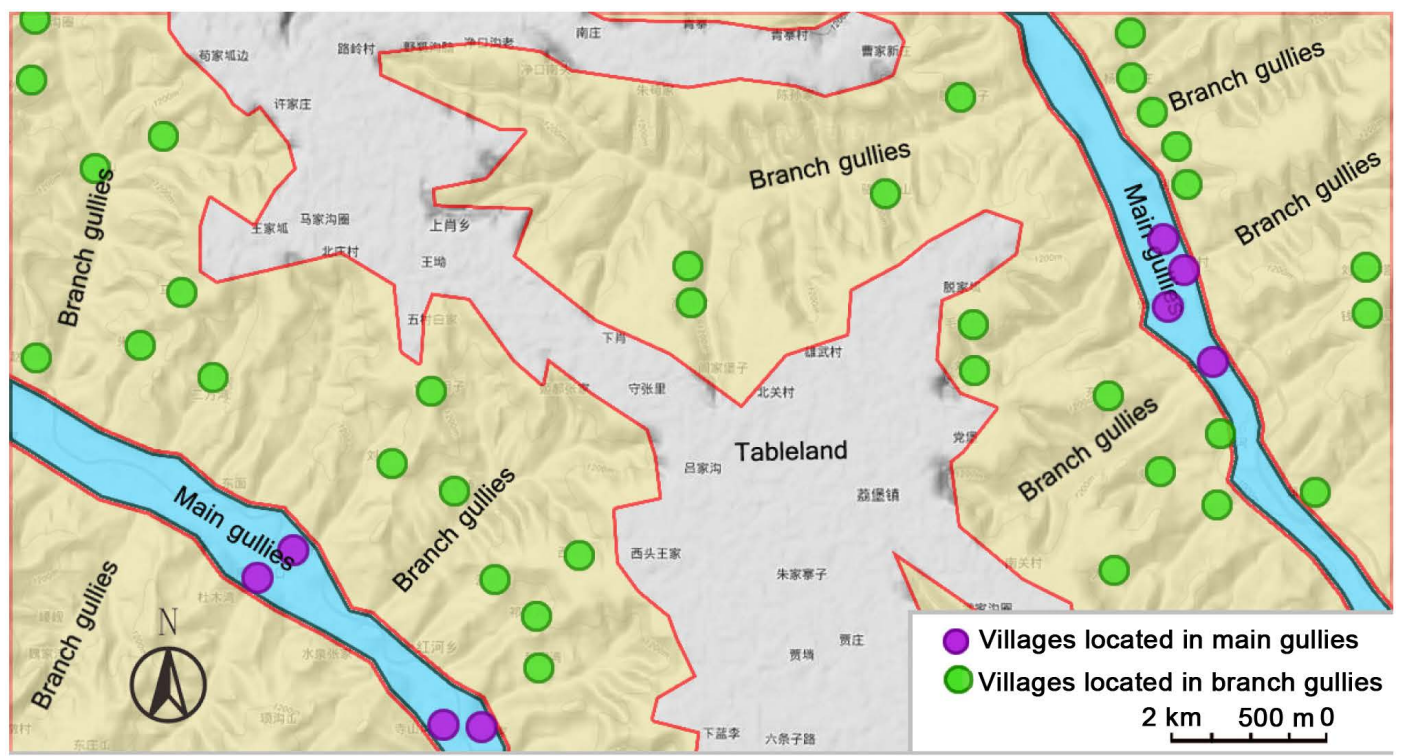

Figure 3. The two kinds of gully villages.

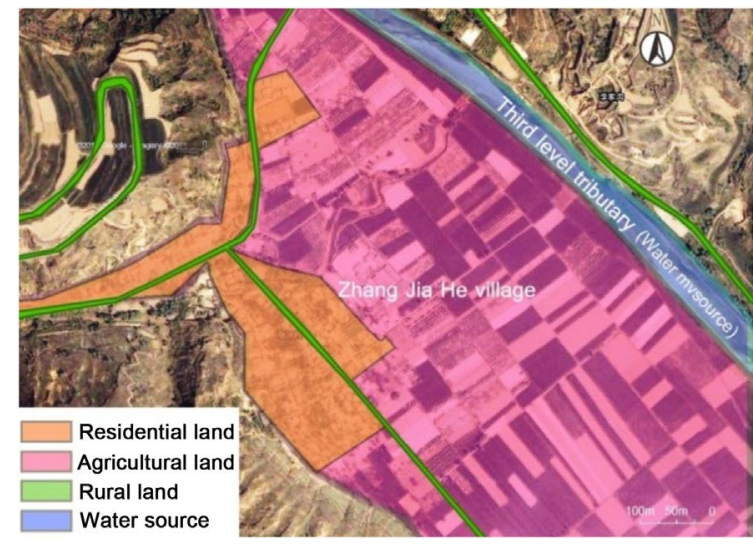

Land distribution of Zhang Jia He village

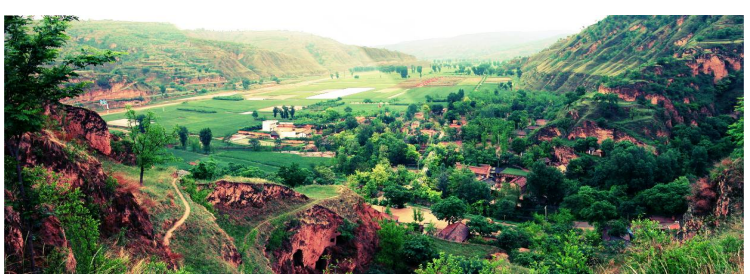

Existing condition of Zhang Jia He village

Figure 4. Zhang Jia He village located in main gullies. 
2) Villages located in branch gullies

Because of limited geography, the villages located in branch gullies of the third level tributary, in form of a closed space, which creates an independent, quiet and harmonious neighborhood living unit in Loess Plateau. The villages have a small size with small number of population. The following figures show a typical branch gully village, the name of village is Wu Jia Shan village. There are 68 families, 258 people, and 30.93 hectares of cultivated land. There is no primary school and clinic, meanwhile, infrastructure is poor. Annual per-capita income is less 2000RMB (327 USD) (Figure 5).

\section{Methodology}

Although the distribution of gully villages in main gullies and branch gullies are different, their component elements, distribution forms and the developing influenced elements are almost the same. As there is not much difference between these two kinds of villages, only for the developing conditions are different, they are different. Thus this study uses a same method to evaluate these two kinds of villages. Based on the established ecological system of tableland, the ecological construction of gully villages aims to achieve sustainable development through practical investigation, documentation research, and by contemporary ecological theory and methods. The process of evaluation is shown in Figure 6.

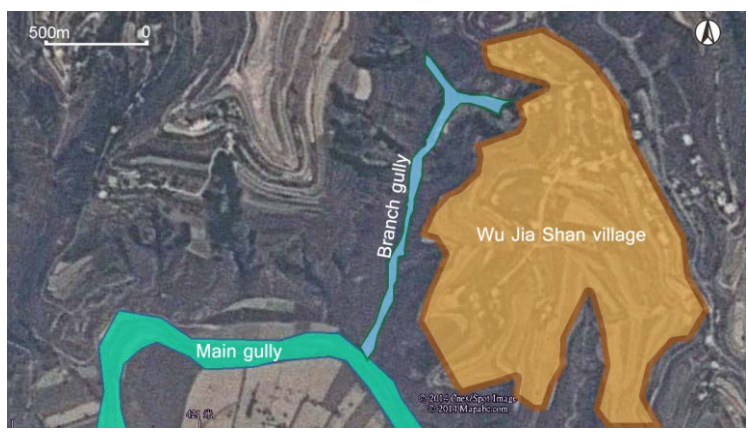

Present distribution of Wu Jia Shan village

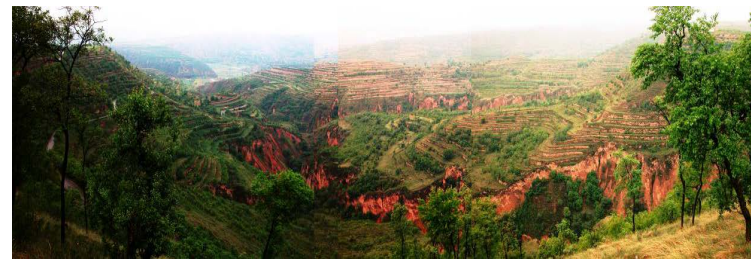

Existing condition of Wu Jia Shan village

Figure 5. Wu Jia Shan village located in branch gullies.

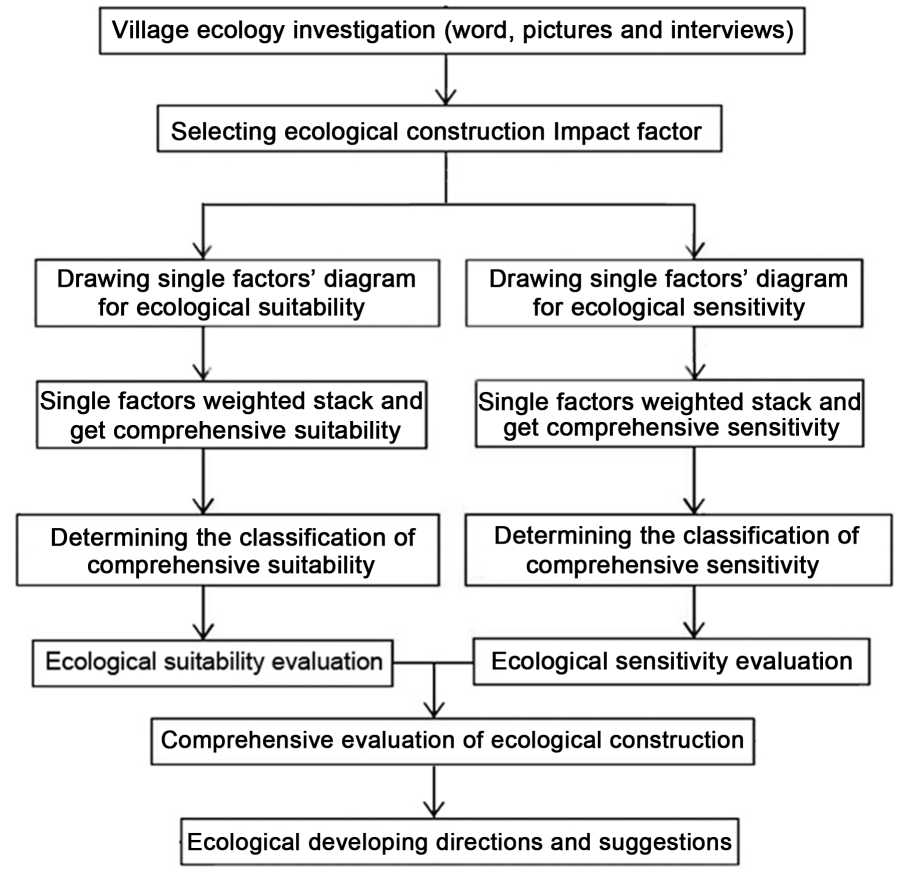

Figure 6. Analysis process of quantitative evaluation. 
The determination of index factors used in the process of ecological suitability and sensitivity evaluation makes possible for evaluating the effects of ecological construction by qualitative and quantitative methods. The ecological index evaluation of gully villages' human living ecology is a typical multi-objective decision; each index reflects the importance on ecology. Due to the different contributions of these index factors to the ecological aim, these factors should be treated differently during the process of comprehensive evaluation [7].

For this reason, the sequencing of index factors with different degree is the basis for the evaluation, and it is also show the understanding of society, economy, the nature, and the implement of governmental guidelines. At present, there is no systematic data statistics of related data in the gully regions. In this research, the index weights are mainly according to large amount of literature review and field research. Basic data are mainly received from local governments and villagers during the field research. According to the importance of factors on people's production and living, these factors are estimated and classified.

\section{Ecological Suitability Evaluation}

Evaluation on the suitability of ecological construction is based on weighted grading method [8]. Firstly, identifying the evaluation factors that have influence on the villages' ecological suitability, and then investigating the distribution and characteristics of each factor and classifying them. Secondly, according to the effects on the villages' ecological construction, factors' importance will be identified. More weights will be put to those factors that own more effects on ecological construction. Finally, on the basis of classification, all factors will be weighted sum, thus the result shows the comprehensive evaluation value for suitability.

The main ideas can be listed as the following:

1) The selection and classification of suitability evaluation factors. The factors' suitability can classify into 5 , 3,1 , which can also be used to show the suitability levels of ecological construction of gully villages [9]. 2) Assessment and evaluation of the weight value of each factor, and drawing a hierarchical graph for each factor. 3) Single factor is stacked and classified according to the stacked results. 4) According to the result of suitability evaluation, factors are divided into three different ranges: suitable, more suitable, not suitable, and the suitability of ecological construction are divided into good, general and poor.

\subsection{Selection of Evaluation Factors}

According to different influence factors on production, living and adapting methods, and documents utility, author selected ten evaluation factors: 1) slope gradient of both slopes in gullies, 2) gully width, 3) surface water, 4) cultivated land per capita, 5) population size, 6) transportation, and 7) village land use degrees, 8) soil productivity, 9) plants diversity, and 10) public infrastructure. Ten evaluation factors are described as follows:

1) Slope gradient of both slopes in gullies

The influence caused by slope gradient is one of the most important factors for land suitability. According to the research of runoff plots of soil and water conservation, if the slope gradient is within $30^{\circ}$ and under the same utilization conditions, the bigger the slope gradient, the soil and water erosion will be worse, and soil productivity will be lower thus slope gradient and soil and water erosion is positive correlated [10]. The weight is 0.100 .

- Slope gradient $<5^{\circ}$ : basically is flat land, soil erosion which is suitable land for village development. The evaluation value is 5 .

- Slope gradient $5^{\circ}-25^{\circ}$ : have a certain slope gradient, which can be use for terrace field. There are limitations for villages' development. The evaluation value is 3 .

- Slope gradient $>25^{\circ}$ : slope gradient is large, the farmland there should be returned into forest or grass land. The limitation for villages' development is large. The evaluation value is 1 .

2) Gully width

Gully width directly limits the scale of village land use, land area, thus affecting the development of the whole village. The weight is 0.125 .

- Gully width $>300 \mathrm{~m}$ : there is enough developing space that can satisfy the demand for village development. The evaluation value is 5 .

- Gully width $100 \mathrm{~m}$ - $300 \mathrm{~m}$ : land scale is general and there is not too much space for further development. The evaluation value is 3 .

- Gully width $<100 \mathrm{~m}$ : land scale is too small and unsuitable for villages' development. The evaluation value is. 


\section{3) Surface water}

Surface water is one of the very important elements for wild animals and natural ecological system. Thus water area is a judge standard. The weight is 0.075 .

- Gully villages are located in the area of reservoir and the coverage area. The evaluation value is 5.

- Gully villages are located in the coverage area of rivers or springs. The evaluation value is 3.

- Gully villages are located in the no water area. The evaluation value is 1 .

4) Cultivated land per capita

Cultivated land per capita is the most important production condition and essential guarantee for certain productivity. The weight is 0.100 .

- $\quad$ >3.0 mu/per: villagers have large area of production land and in good condition, thus good living conditions can be guaranteed. The evaluation value is 5 .

- 1.5 - 3.0 mu/per: Production land is enough and villagers' living conditions can be guaranteed. The evaluation value is 3 .

- $\quad<1.5 \mathrm{mu}$ /per: Production land is not enough and in bad conditions, villagers' life is very hard. The evaluation value is 1 .

5) Population size

Population size is the basic element to ensure the villager development. The weight is 0.100 .

- >300: population is large size and developing conditions are related mature, which is suitable for further development. The evaluation value is 5 .

- 100 - 300: Population is moderate size and developing conditions are relatively common, which can be reserved and developed. The evaluation value is 3 .

- $\quad<100$ : Population is relatively small size and developing conditions are relatively poor, which is better to relocate to other places. The evaluation value is 1 .

6) Transportation

Numerous gullies, fragment landform and lower accessibility are the main characteristics of gully villagers' transportation. Thus, transportation is the main index to measure the accessibility and convenience among cities and towns, which own the positive relation with villagers' development degree [11]. The weight is 0.100.

- Transportation joint: the joint of logistics, energy flow, information flow and species flow. The evaluation value is 5 .

- Beside transportation thoroughfares: the place that logistics, energy flow, information flow and species flow pass. The evaluation value is 3 .

- Faraway from transportation thoroughfares: the place is far away from logistics, energy flow, information flow and species flow. The evaluation value is 1 .

7) Village land use degrees

Village land use degree is an important influence factor for developing invest and construction, which is also one of the basis for deciding villagers developing directions in a period of planning process. The higher degree of land use means the larger population and the bigger developing potential. It is how that the proportion of existing residential area. The weight is 0.100 .

- Village land use degree $>30 \%$ : The proportion of residential land use is high. The evaluation value is 5 .

- Village land use degree 5\% - 30\%: The proportion of residential land use is relatively high. The evaluation value is 3 .

- Village land use degree $<5 \%$ : The proportion of residential land use is low. The evaluation value is 1.

8) Soil productivity

Soil productivity refers to the food production capacity and quantity in farmland per unit, and also the comprehensive reflection of effective thickness of soil layer, soil organic elements, and water condition and soil texture. The weight is 0.125 .

- High productivity: effective thickness of soil layer $>200 \mathrm{~cm}$, soil organic elements $>1.2 \%$ soil texture is medium loam, no soil erosion. The evaluation value is 5 .

- Medium productivity: effective thickness of soil layer $100-200 \mathrm{~cm}$, soil organic elements $1 \%$ - $1.2 \%$, soil texture is light loam, soil erosion is middle degree. The evaluation value is 3.

- Low productivity: effective thickness of soil layer $<100 \mathrm{~cm}$, soil organic elements $<1 \%$, soil texture is sandy loam, soil erosion is high degree. The evaluation value is 1 .

9) Plants diversity 
Plants play very important ecological functions in protecting natural sources, and stabilizing gully and slope, soil and water conservation, improvement of fragile ecological environment and anti-interference ability, reduction of ecological sensitivity variation. Plants can be classified in the following three kinds according to their species, areas and values. The weight is 0.075 .

- Dense forest zone: mainly with natural vegetation and rich in wild animals. The evaluation value is 5.

- Half forest and half village zone: mainly with artificial vegetation and farmland plants. The evaluation value is 3 .

- No vegetation zone: mainly with farmland plants and without natural vegetation and wild animals. The evaluation value is 1 .

10) Public infrastructure degrees

Public infrastructure is the important guarantee for life, the developing level of which is one of the important elements to measure the degree of life convenience. The weight is 0.100 .

According to the conditions and distribution, and take the reference of the public infrastructure standards, public infrastructure can be divided into good, general and poor.

\subsection{Standards for the Suitability}

According to the grading standards of single factors, a hierarchical graph can be made and the evaluation results of single factors should also be stacked. Using weighting factor method to evaluate, the computational formula is:

$$
S_{i}=\sum_{k=1}^{n} B_{k i} W_{k}
$$

In Equation (1):

$i$-refers to the name of gully village, whose ecological construction conditions will be evaluated.

$k$-refers to the serial number of evaluation factors for ecological suitability evaluation.

$n$-refers to the total number of factors for ecological suitability evaluation.

$W_{k}$-weight value of factor $k$ for ecological suitability evaluation, $W_{1}+W_{2}+\ldots+W_{\mathrm{k}}=1$.

$B_{k i}$ - suitability evaluation value of factor $k$ in gully village $i$.

$S_{i}$ - comprehensive evaluation value of ecological suitability in gully village $i$.

In Table 1, the comprehensive value of all stacked factors is changing within 1.00 - 5.00, in order to combine the future developing strategy with suitability evaluation, this paper divides the suitability evaluation into three levels: 1) $3.70<S \leq 5.00$, villages with good suitability of ecological construction. 2) $2.40<S \leq 3.70$, villages with general suitability of ecological construction. 3) $1.00<S \leq 2.40$, villages with poor suitability of ecological construction [9].

\section{Ecological Sensitivity Evaluation}

Ecological sensitivity refers to the ecological factors' adaptability under the outside pressure or interference without damage or lower environmental quality [12]. Different ecological system responses differently for human activities, some of them own strong resistance, while some systems are fragile. The aim of ecological sensitivity is to analyze the responses of village natural ecological system to human activities.

Factors' weighted grading method is adopted for evaluating the ecological sensitivity of gully villages. Firstly, identifying the evaluation factors that have influence on the villages' ecological sensitivity, and then investigating the distribution and characteristics of each factor and classifying them. Secondly, according to their effects on the villages' ecological construction, factors' importance will be identified. More weights will be put to those factors that own more effects on ecological construction. Finally, on the basis of classification, all factors will be weighted sum, thus get the comprehensive evaluation value for sensitivity. The basic method is as the following:

1) The selection and classification of ecological sensitivity factors. The factors' sensitivity can classify into 5 , 3,1 , which can also be used to show the sensitivity levels of ecological construction of gully villages [9]. 2) Deciding the weights of each factor and evaluating one by one, and making the hierarchical graph for each factor. 3) Single factor is stacked and classified according to the stacked results. 4) According to the result of sensitivity evaluation, ecological sensitivity values can be divided into three degrees: high, general, and low ecological sensitivity, villages can be divided accordingly into high, general and low ecological sensitivity villages. 
Table 1. Standards and weights of suitability evaluation factors in gully villages’ ecological construction.

\begin{tabular}{|c|c|c|c|c|}
\hline Ecological factors & Evaluation standards & Classification & $\begin{array}{l}\text { Evaluation } \\
\text { value }\end{array}$ & Weights \\
\hline \multirow{3}{*}{$\begin{array}{l}\text { Slope gradient } \\
\text { of both slopes } \\
\text { in gullies }\end{array}$} & \multirow{3}{*}{$\begin{array}{l}\text { The smaller the slope gradient is, the higher } \\
\text { suitability of ecological construction }\end{array}$} & $<5^{\circ}$ & 5 & \multirow{3}{*}{0.100} \\
\hline & & $5^{\circ}-25^{\circ}$ & 3 & \\
\hline & & $>25^{\circ}$ & 1 & \\
\hline \multirow{3}{*}{ Gully width } & \multirow{3}{*}{$\begin{array}{l}\text { The wider the gully is, the higher } \\
\text { suitability of ecological construction }\end{array}$} & $>300 \mathrm{~m}$ & 5 & \multirow{3}{*}{0.125} \\
\hline & & $100 m-300 m$ & 3 & \\
\hline & & $<100 \mathrm{~m}$ & 1 & \\
\hline \multirow{3}{*}{ Surface water } & \multirow{3}{*}{$\begin{array}{l}\text { The better the surface water is, the higher } \\
\text { suitability of ecological construction }\end{array}$} & Reservoir and the coverage area & 5 & \multirow{3}{*}{0.075} \\
\hline & & Rivers and springs & 3 & \\
\hline & & No water areas & 1 & \\
\hline \multirow{3}{*}{$\begin{array}{l}\text { Cultivated } \\
\text { land per capita }\end{array}$} & \multirow{3}{*}{$\begin{array}{l}\text { The larger the cultivated land per capita is, } \\
\text { the higher suitability of ecological construction }\end{array}$} & $>3.0 \mathrm{mu} / \mathrm{per}$ & 5 & \multirow{3}{*}{0.100} \\
\hline & & 1.5 - $3.0 \mathrm{mu} / \mathrm{per}$ & 3 & \\
\hline & & $<1.5 \mathrm{mu} / \mathrm{per}$ & 1 & \\
\hline \multirow{3}{*}{ Population size } & \multirow{3}{*}{$\begin{array}{l}\text { The larger the population size is, the higher } \\
\text { suitability of ecological construction }\end{array}$} & $>300$ people & 5 & \multirow{3}{*}{0.100} \\
\hline & & 100 - 300 people & 3 & \\
\hline & & $<100$ people & 1 & \\
\hline \multirow{3}{*}{ Transportation } & \multirow{3}{*}{$\begin{array}{l}\text { The better the transportation is, the higher } \\
\text { suitability of ecological construction }\end{array}$} & Transportation joint & 5 & \multirow{3}{*}{0.100} \\
\hline & & Transportation thoroughfares & 3 & \\
\hline & & $\begin{array}{l}\text { Faraway from } \\
\text { transportation thoroughfares }\end{array}$ & 1 & \\
\hline \multirow{3}{*}{$\begin{array}{l}\text { Village } \\
\text { land use } \\
\text { degrees }\end{array}$} & \multirow{3}{*}{$\begin{array}{l}\text { The higher the village land use degrees are, } \\
\text { the higher suitability of ecological construction }\end{array}$} & $>30 \%$ & 5 & \multirow{3}{*}{0.100} \\
\hline & & $5 \%-30 \%$ & 3 & \\
\hline & & $<5 \%$ & 1 & \\
\hline \multirow{3}{*}{$\begin{array}{c}\text { Soil } \\
\text { productivity }\end{array}$} & \multirow{3}{*}{$\begin{array}{l}\text { The better the soil productivity is, the higher } \\
\text { suitability of ecological construction }\end{array}$} & High productivity & 5 & \multirow{3}{*}{0.125} \\
\hline & & Medium productivity & 3 & \\
\hline & & Low productivity & 1 & \\
\hline \multirow{3}{*}{ Plants diversity } & \multirow{3}{*}{$\begin{array}{l}\text { The more diversity the plants are, the higher } \\
\text { suitability of ecological construction }\end{array}$} & Dense forest zone & 5 & \multirow{3}{*}{0.075} \\
\hline & & Half forest and half tillage zone & 3 & \\
\hline & & No vegetation zone & 1 & \\
\hline \multirow{3}{*}{$\begin{array}{c}\text { Public } \\
\text { infrastructure } \\
\text { degrees }\end{array}$} & \multirow{3}{*}{$\begin{array}{l}\text { The higher lever the public infrastructure degrees are, } \\
\text { the higher suitability of ecological construction }\end{array}$} & Good & 5 & \multirow{3}{*}{0.100} \\
\hline & & General & 3 & \\
\hline & & Poor & 1 & \\
\hline
\end{tabular}

\subsection{Selection of Evaluation Factors}

Taking the gully nature and social economy into consideration, there are six limitation factors: 1) slope gradient of gully slopes, 2) soil erodibility, 3) surface runoff sediments, 4) soil and water loss, 5) plant coverage, 6) pollution. Table 2 shows the different influence degrees of human activity of these six factors.

1) Slope gradient and length of both slopes 
Table 2. Standards and weights of sensitivity evaluation factors in gully villages’ ecological construction

\begin{tabular}{|c|c|c|c|c|}
\hline Ecological factors & Evaluation standards & Classification & $\begin{array}{l}\text { Evaluation } \\
\text { value }\end{array}$ & Weights \\
\hline \multirow{3}{*}{$\begin{array}{l}\text { Slope gradient } \\
\text { and length }\end{array}$} & \multirow{3}{*}{$\begin{array}{l}\text { The bigger the slope gradient and length is, } \\
\text { the higher sensitivity of ecological construction }\end{array}$} & $>25^{\circ},<12 \mathrm{~m}$ & 5 & \multirow{3}{*}{0.250} \\
\hline & & $5^{\circ}-25^{\circ}, 12 \mathrm{~m}-60 \mathrm{~m}$ & 3 & \\
\hline & & $<5^{\circ},>60 \mathrm{~m}$ & 1 & \\
\hline \multirow{3}{*}{ Soil erodibility } & \multirow{3}{*}{$\begin{array}{l}\text { The higher the soil erodibility is, } \\
\text { the higher sensitivity of ecological construction }\end{array}$} & Sandy soil, clay & 5 & \multirow{3}{*}{0.250} \\
\hline & & Light loam & 3 & \\
\hline & & Medium loam & 1 & \\
\hline \multirow{3}{*}{$\begin{array}{l}\text { Surface } \\
\text { runoff } \\
\text { sediments }\end{array}$} & \multirow{3}{*}{$\begin{array}{l}\text { The more surface runoff sediment is, } \\
\text { the higher sensitivity of ecological construction }\end{array}$} & Runoff and sediments collecting area & 5 & \multirow{3}{*}{0.100} \\
\hline & & Runoff and sediments source area & 3 & \\
\hline & & Runoff and sediments formative area & 1 & \\
\hline \multirow{3}{*}{$\begin{array}{l}\text { Soil and } \\
\text { water loss }\end{array}$} & \multirow{3}{*}{$\begin{array}{l}\text { The more serious the soil and water loss is, } \\
\text { the higher sensitivity of ecological construction }\end{array}$} & Serious & 5 & \multirow{3}{*}{0.150} \\
\hline & & General & 3 & \\
\hline & & Slight & 1 & \\
\hline \multirow{3}{*}{$\begin{array}{l}\text { Plants } \\
\text { coverage }\end{array}$} & \multirow{3}{*}{$\begin{array}{l}\text { The more the plants coverage is, } \\
\text { the higher sensitivity of ecological construction }\end{array}$} & $<50 \%$ & 5 & \multirow{3}{*}{0.150} \\
\hline & & $50 \%-90 \%$ & 3 & \\
\hline & & $>90 \%$ & 1 & \\
\hline \multirow{3}{*}{ Pollution } & \multirow{3}{*}{$\begin{array}{l}\text { The more serious pollution is, } \\
\text { the higher sensitivity of ecological construction }\end{array}$} & High & 5 & \multirow{3}{*}{0.100} \\
\hline & & Medium & 3 & \\
\hline & & Low & 1 & \\
\hline
\end{tabular}

Slope gradient and length is an important factor that influences soil erosion sensitivity. Under a certain condition, the same slope gradient but longer slope, the kinetic energy of water flow is larger, soil erosion intensity is higher, geological conditions is less stable, thus it is very sensitive for human activity. The weight is 0.250 .

- Slope gradient $<5^{\circ}$, slope length $<12 \mathrm{~m}$ : Basically are flat land and the ideal land for village development. The evaluation value is 5 .

- Slopes gradient $5^{\circ}-25^{\circ}$, slope length $12 \mathrm{~m}$ - $60 \mathrm{~m}$ : Have a certain slope gradient, which can be used for terrace field. There are a certain limitations for villages’ development. The evaluation value is 3 .

- Slope gradient $>25^{\circ}$, slope length $>60 \mathrm{~m}$ : The slope is large, slope gradient is large, the farmland there should be returned into forest or grass land. The limitation for villages' development is large. The evaluation value is 1 .

2) Soil erodibility

The higher the soil erodibility is, the erosion sensitivity will be higher. The weight is 0.250 .

- $\quad$ Sandy soil, clay. The evaluation value is 5 .

- Light loam. The evaluation value is 3 .

- Medium loam. The evaluation value is 1 .

3) Surface runoff sediments

Surface runoff sediments is the most direct motivation for soil and water loss, thus kinetic energy of surface water and sediment movement is the most important factor to evaluate the soil erosion sensitivity. The weight is 0.100 .

- Runoff and sediments collecting area. The evaluation value is 5.

- Runoff and sediments source area. The evaluation value is 3.

- Runoff and sediments formative area. The evaluation value is 1 .

4) Soil and water loss

The more serious the soil erosion means that ecology is more sensitive to human activity, which can be di- 
vided into serious, the evaluation value is 5 ; general, the evaluation value is 3 ; and slight, the evaluation value is 1. The weight is 0.150 .

5) Plants coverage

The rain erosion and kinetic energy of water flow can be reduced greatly if the soil is covered by plants. At the same time, rainfall infiltration and surface runoff can be increased, thus reduces the soil erosion. Therefore, plants coverage is an important factor that influences soil erosion sensitivity. The weight is 0.150 .

- Plants coverage > 90\%: Means that plant coverage area accounts for more than $90 \%$ of unit area. The evaluation value is 5 .

- Plants coverage 50\% - 90\%: Plant coverage area accounts for 50\% - 90\% of unit area. The evaluation value is 3.

- Plants coverage $<50 \%$ : Plant coverage area accounts for less than $50 \%$ of unit area. The evaluation value is 1.

6) Pollution

Pollution caused by industry, agriculture, domestic pollution, and can be divided into high, the evaluation value is 1 ; medium, the evaluation value is 3 ; and low, the evaluation value is 1 . The weight is 0.100 .

\subsection{Standards for the Sensitivity}

According to the hierarchical graph of single factors, factors should be stacked. Then using weighting factor method to evaluate, the following is computational formula:

$$
S_{i}^{\prime}=\sum_{k=1}^{n} B_{k i}^{\prime} W_{k}^{\prime}
$$

In the equation:

$i$-refers to the name of gully village, whose ecological construction conditions will be evaluated.

$k$-refers to the serial number of evaluation factors for ecological sensitivity evaluation.

$n$-refers to the total number of factors for ecological sensitivity evaluation.

$W_{k}^{\prime}$-weight value of factor $k$ for ecological sensitivity evaluation, $W_{1}+W_{2}+\ldots+W_{k}=1$.

$B_{k i}^{\prime}$ - sensitivity evaluation value of factor $k$ in gully village $i$.

$S_{i}^{\prime}$ - comprehensive evaluation value of ecological sensitivity in gully village $i$.

In Table 2, the comprehensive value of all stacked factors is changing within 1.00 - 5.00, in order to combine the future developing strategy with sensitivity evaluation, this paper divides the suitability evaluation into three levels: 1) $3.70<\mathrm{S} \leq 5.00$, villages with high ecological sensitivity. 2) $2.40<\mathrm{S} \leq 3.70$, villages with general ecological sensitivity. 3) $1.00<\mathrm{S} \leq 2.40$, villages with poor ecological sensitivity [9].

\section{Developing Direction of Gully Villages}

According to the ecological suitability and sensitivity evaluation of gully villages, the developing condition can be divided into "Good", "General” and "Poor":

- "Good" is defined that the comprehensive evaluation for ecological suitability $>3.70$, and ecological sensitivity $\leq 2.40$.

- "General" is defined that the comprehensive evaluation for ecological suitability $>2.40$, and ecological sensitivity $\leq 3.70$.

- "Poor" is defined that the comprehensive evaluation for ecological suitability $<2.40$, and ecological sensitivity $>3.70$.

If the self-conditions is the basic requirement for the ecological construction and social development of gully villages, then the ecological developing conditions of surrounding villages also play an important role in it. On the basis of quantitative and qualitative analyses of self-conditions of gully villages, this paper also analyze the relationship between gully villages and the surrounding villages. The surrounding villages' developing level can directly or indirectly contribute the developing directions of gully villages. Combining with the surrounding villages' developing situation, Table 3 analyzes the future developing directions for gully villages with different ecological construction. 
Table 3. The future developing directions for gully villages

\begin{tabular}{|c|c|c|}
\hline $\begin{array}{l}\text { Distribution of } \\
\text { surrounding villages }\end{array}$ & $\begin{array}{l}\text { Ecological self-conditions } \\
\text { of gully villages }\end{array}$ & Future developing directions \\
\hline \multirow{3}{*}{$\begin{array}{l}\text { Large villages } \\
\text { with good developing } \\
\text { conditions }\end{array}$} & Good & $\begin{array}{l}\text { Villages can develop by themselves, and also can be } \\
\text { merged into the surrounding villages with better developing conditions. }\end{array}$ \\
\hline & General & $\begin{array}{l}\text { It is better to be merged into the surrounding villages with better } \\
\text { developing conditions, and also they can develop by themselves. }\end{array}$ \\
\hline & Poor & $\begin{array}{c}\text { These villages should be merged into the surrounding village } \\
\text { with better developing conditions. }\end{array}$ \\
\hline \multirow{3}{*}{$\begin{array}{l}\text { General size villages } \\
\text { with general } \\
\text { developing conditions }\end{array}$} & Good & $\begin{array}{l}\text { It is better to develop independently, and also they } \\
\text { can merge into the surrounding villages. }\end{array}$ \\
\hline & General & $\begin{array}{l}\text { Villages can develop by themselves, and also can be merged } \\
\text { into the surrounding villages with better developing conditions. }\end{array}$ \\
\hline & Poor & $\begin{array}{c}\text { These villages should be merged into the surrounding villages } \\
\text { with better developing conditions. }\end{array}$ \\
\hline \multirow{3}{*}{$\begin{array}{c}\text { Small size villages } \\
\text { with poor developing } \\
\text { conditions }\end{array}$} & Good & $\begin{array}{l}\text { These villages should merge with the small size villages } \\
\text { with poor developing conditions. }\end{array}$ \\
\hline & General & $\begin{array}{l}\text { These villages can develop by themselves, and also can be merged } \\
\text { into the surrounding villages with better developing conditions. }\end{array}$ \\
\hline & Poor & $\begin{array}{l}\text { These villages can merge with the surrounding villages, } \\
\text { and also can be moved to other areas. }\end{array}$ \\
\hline \multirow{3}{*}{$\begin{array}{l}\text { No villages } \\
\text { distribution }\end{array}$} & Good & These villages should develop independently. \\
\hline & General & $\begin{array}{l}\text { These villages should develop independently, } \\
\text { and also can be move to other areas. }\end{array}$ \\
\hline & Poor & These villages should be move to other areas. \\
\hline
\end{tabular}

\section{Conclusions}

China, as the largest developing country in the world, is experiencing rapid development now. Along with this rapid development and recent new socialist rural construction, gully villages of Loess Plateau are also experiencing a great change. How to make them to achieve a better development in the future is a big challenge for this region. At the same time, as one of the most fragile ecological area in China, it is very significant to improve their soil and water protection, ecological system, during the whole developing process.

This paper studies the gully villages of Loess Plateau in detailed, which are very typically facing "death" in recent years, and finds out factors that influences ecological construction and development. The classification of suitability and sensitivity factors of ecological construction makes it possible to evaluate the efficiency of ecological construction by qualitative and quantitative evaluation, and at the same time provides as the basis for ecological management. However, human living's ecological environment of gully village is continuous developing. These independent and limited index factors are impossible to reflect overall functions, structure relationships, developing levels and tendency. The comprehensive index system is not necessary and sufficient. And these standards are not absolute suitable for ecological construction. They must combine with specific time, space and social conditions. Therefore, what could be provided here are only relative references, which are imprecise and periodically. This paper hopes to explore a new way for the future development of gully villages, and provides reference and guidance for better and scientific development in the future.

\section{Acknowledgements}

1) Supported by the National R \& D Infrastructure and Facility Development Program of China (2007 DKA 32300-12)

2) Supported by Science and technology research and development project of Shaanxi Province (2010K01-123)

\section{References}

[1] Zhang, T.Z. (1993) Contention of Key Issues in China’s Loess Plateau. China Environmental Science Press, Beijing. 
[2] Cao, X.M. and Zhou, R.Q. (2008) The Spatial Features and Leading Measures of Village System in Small Watershed in Loess Plateau Gully Region-A Case Study on Chunhua County, Shaanxi Province. Human Geography, 5, 015. http://en.cnki.com.cn/Journal_en/F-F089-RWDL-2008-05.htm

[3] Lu, X.Q. (2013) Dispersed and Clustered: Rural Settlement Patterns and Its Evolution in Traditional China. Journal of Huazhong Normal University (Humanities and Social Sciences), 4, 016. http://en.cnki.com.cn/Journal_en/H-H000-HZSD-2013-04.htm

[4] Yu, H. X., Zhou, R.Q. and Liu, L.A. (2005) Ecological Approach to Human Settlement Planning in Small Watershed Gully Areas on the Loess Plateau-With the Example of Zaozigou Small Watershed in North Shaanxi. Journal of Xian University of Architecture \& Technology, 2, 189-193. http://en.cnki.com.cn/Journal en/C-C000-XAJZ-2005-02.htm

[5] Zhou, Q.H. (2004) On the Urban Spatial Form Evolution in Shanbei Loess Plateau Region from the Ecological Viewpoint. Urban Planning Forum, 4, 018. http://en.cnki.com.cn/Journal_en/C-C038-CXGH-2004-04.htm

[6] Wang, L. (2005) Study on the Urban Waterfront in Small-Scale Towns of Northern Shannxi-Take Two Towns for Instance: Suide and Mizhi. Master. Thesis, Xi'an University of Architecture \& Technology, Xi'an.

[7] Chen, L., Wei, W., Fu, B. and Lü, Y. (2007) Soil and water Conservation on the Loess Plateau in China: Review and Perspective. Progress in Physical Geography, 31, 389-403. http://dx.doi.org/10.1177/0309133307081290

[8] Wang, Y.S. and Lv, X.H. (2011) Research on the Ecological Suitability of Location and Layout for the Traditional Based-on-GIS Mountain Village. Huazhong Architecture, 10, 034. http://en.cnki.com.cn/Journal_en/C-C038-HZJZ-2011-10.htm

[9] Yu, H.X. (2007) A Study of Ecologic Theory and Plan-Designing Methods for Human Habitat in Gully Region on Loess Plateau. Ph.D. Thesis, Xi'an University of Architecture \& Technology, Xi'an.

[10] Zhang, M.S., Han, Q.L., Huang, Y.H. and Hu, W. (2011) A Study of Remediation of Valley-Type Landslides in the Loess Plateau: Exemplified by the Yanjiagou Landslide in Zichang County of Yan’an. Hydrogeology \& Engineering Geology, 2, 026. http://en.cnki.com.cn/Article_en/CJFDTOTAL-HZSD201304016.htm

[11] Feng, Z.M., Liu, D. and Yang, Y.Z. (2009) Evaluation of Transportation Ability of China: From County to Province Level. Geographical Research, 28, 419-429. http://en.cnki.com.cn/Journal_en/A-A008-DLYJ-2009-02.htm

[12] Jun, L.I., Cao, M.M., Qiu, H.J., Sheng, H.U., Hao, J.Q. and Liu, W. (2014) The Assessment of GIS-Based Land EcoEnvironmental Sensitivity of Xi'an City. Journal of Northwest University, 1, 121-127. http://en.cnki.com.cn/Journal_en/A-A000-XBDZ-2014-01.htm 